\title{
Designing interactive museum visitors' experience using a Fab Living Lab platform: the Museum- Aquarium of Nancy case
}

\author{
Ievgeniia Ten, Giovanny Arbelaez-Garces, Laurent Dupont \\ Université de Lorraine, ERPI, F-54000 Nancy, France \\ arbelaez5@univ-lorraine.fr
}

\begin{abstract}
As in many areas, museums and cultural institutions currently undergo a transformation characterized by the use of digital and interactive technologies. New perspectives in the development of museum experiences are being open which impacts the overall functioning of these institutions. To design experiences that are adapted to enhance the visitor experience appropriate methods are required. User experience design and Living labs approach offer tools to support this process. In this paper, we document the experience of the renovation of the Museum-Aquarium in interaction with the Fab Living Lab platform, the academic innovation space of Nancy, France. We present the process of the development of three interactive and digital experiences based on ideation, rapid-prototyping, and test by use. This experience presents the methods and shares the lessons learned in this process. The work performed can serve as references for the development of other museum interactive installations. Furthermore, we identify potential transfer to other domains.
\end{abstract}

\section{Keywords-User experience, museums, cultural heritage, Living Labs, Boundary Object}

\section{INTRODUCTION}

Digital technology is transforming all domains of society and museums and science centers are not the exception. Museums are interested in providing new interactive experiences to engage their visitors. This transformation process possesses several challenges in particular with its design process [1]. Indeed, designing new interactive experiences requires complementary competencies (e.g. mechanical design, coding, electronic prototyping, HCI, interactive design, among others) and also to implement participatory and agile design practices [2].

Designing a balanced proposal between physical and digital experiences for museum visitors requires a thorough understanding of the institution, its collections, audiences and identity [3], [4]. In short, understanding the complete visitors' user experience [5]. Living labs and user experience (UX) design approaches offer methods and tools for aiding in the construction of new museum experiences through a better understanding of visitors and all the museum stakeholders [5]-[7].

As highlighted by [3] "no one fits all approach" for the digital transformation exist, thus documenting this transformation process is an important practice for knowledge sharing. While previous developments of interactive examples exist, there is still a need to share detailed experiences documenting their processes on how the interactivity development challenge has been tackled in museums and cultural heritage institutions. For this reason, in this paper, we present the experience of the renovation of the Museum-Aquarium in Nancy France (MAN) that reopened in 2019. In particular, we present the process of development of three interactive and digital experiences by one Master student in design and innovation, based on a Fab Living Lab approach merging Creativity, Living Lab and Fablabs concepts in one original academic innovation space, where innovation is developed in particular through Boundary Objects (BO). This place is supported and used by Academics (researchers, school of engineers), local companies and public institutions. This experience presents the methods used and how they were inspired by innovation management, agile development practices, and physical prototyping. Furthermore, this study presents how a young professional acquires the methods and uses the innovation space to collaborate with the museum.

The redesign of the new organization of the museum experience encompassed many exciting and innovative concepts, which envisioned the use of cutting-edge technology. To verify the concept's feasibility, we tested them through a Living Lab approach (this approach was previously used in the same museum [6]). Putting some of the ideas into practice in semi-real situations allows us to test and refine them. The presented cases show implemented projects as part of the museum experience that demonstrates various ways of integrating new technologies into museum functionality. The work performed can serve as reference for the development of other museum interactive installations, information support, and digital resources. The rest of this paper is structured as follows. In section 2, a brief overview of related examples of interactive experiences in museums is presented. Section 3 presents the proposed research approach. Section 4 presents in detail the developed projects. Finally, conclusions and perspectives for further research are presented.

\section{PREVIOUS WORKS}

\section{A. Interactive experiences in museums}

The museum experience is being actively transformed and new technologies are increasingly involved in this process [3], [6]. In most cases, and regardless of the theme, exhibitions are accompanied by established information displays, tablets, mobile technologies, and in some cases virtual reality [8], [9]. Such digital technologies provide multiple opportunities in the

Draft - Authors' version.

Cite final version as: Ten, I., Arbelaez-Garces, G., \& Dupont, L. (2020). Designing interactive museum visitors' experience using a Fab Living Lab platform: the Museum-Aquarium of Nancy case. 2020 IEEE International Conference on Engineering, Technology and Innovation (ICE/ITMC), 1-8. https://doi.org/10.1109/ICE/ITMC49519.2020.9198641 
enrichment of the experience (e.g. interpretation, contextualizing the scenario of a historical event, etc.), which, for some reason, cannot be provided in the real form (for example, an extinct species, a historical object of large scale, etc.). To better understand what type of interactive experiences have been proposed in different museums, we performed a benchmark on this type of initiatives. Table I summarize some implemented examples of the use of new technologies within the scientific, and public cultural institutions context.

TABLE I. EXAMPLE OF INTERACTIVE INSTALLATIONS INVOLVING NEW TECHNOLOGIES WITHIN SCIENTIFIC AND CULTURAL PUBLIC INSTITUTIONS

\begin{tabular}{|c|c|c|}
\hline Title & Where / When & Description \\
\hline $\begin{array}{l}\text { Story of the } \\
\text { Forest }\end{array}$ & $\begin{array}{l}\text { The National Museum of } \\
\text { Singapore } / 2016 \\
\text { (permanent) }\end{array}$ & $\begin{array}{l}\text { Represented by a glass rotunda, which demonstrates the forest world and the animals that inhabit it, due } \\
\text { to musical and graphic elements. Allows the visitor to receive feedback on his movements in the form of } \\
\text { an animated image. Source: https://www.nhb.gov.sg/nationalmuseum/our-exhibitions/exhibition- } \\
\text { list/story-of-the-forest }\end{array}$ \\
\hline $\begin{array}{l}\text { Mona Lisa: } \\
\text { Beyond the } \\
\text { Glass }\end{array}$ & $\begin{array}{l}\text { Louvre Museum / Paris } \\
\text { (temporary: from October } \\
24,2019 \text { to February } 24, \\
2020 \text { ) }\end{array}$ & $\begin{array}{l}\text { Created with the aim that museum visitors could have the opportunity to immerse themselves in the artist's } \\
\text { creative world and get closer to his famous works, including a painting of Mona Lisa. Thus, due to virtual } \\
\text { reality points, the visitor can not only get closer to his paintings, but also contemplate their interpretation } \\
\text { in 3D format. Source: https://www.louvre.fr/mediavideos/mona-lisa-beyond-glass-louvre }\end{array}$ \\
\hline PLUG & $\begin{array}{l}\text { Museum of Arts and Crafts } \\
\text { / Paris(temporary: from } \\
\text { May } 29 \text { to June } 7,2009 \text { ) }\end{array}$ & $\begin{array}{l}\text { Created in order to allow the player to discover the entire physical space of the Museum of Arts and Crafts } \\
\text { and its 4,000 objects, } 16 \text { objects are selected. Virtual playing cards are associated with them. These virtual } \\
\text { playing cards are stored in RFID terminals. Players use mobile phones to read / exchange / deposit cards. } \\
\text { Source: https://www.arts-et-metiers.net/musee/plug-les-secrets-du-musee-du-29-mai-au-7-juin }\end{array}$ \\
\hline $\begin{array}{l}\text { The 3D } \\
\text { Measurement } \\
\text { Cabin }\end{array}$ & $\begin{array}{l}\text { City of Lace and Fashion, } \\
\text { Calais / } 2011 \text { (permanent) }\end{array}$ & $\begin{array}{l}\text { Thanks to the digitalization principle, the 3D measurement cabin creates an avatar of the visitor. Connected } \\
\text { to the cabin, the computer models and displays the silhouette. Once out of the cabin, the visitor can } \\
\text { personalize his profile thanks to a tablet located nearby. He can then walk around the museum virtually, } \\
\text { dress, assemble the pieces of collections as he pleases on display. This innovation is presented as a } \\
\text { mediation tool, a mean of making textile collections accessible while preserving them. Source: } \\
\text { https://www.cite-dentelle.fr/en/home }\end{array}$ \\
\hline $\begin{array}{l}\text { Let's Move } \\
\text { Our Works: } \\
\text { Bring the } \\
\text { Paintings to } \\
\text { Life }\end{array}$ & $\begin{array}{l}\text { The Muséum national Jean- } \\
\text { Jacques Henner / Paris, } \\
2011 \text { (permanent) }\end{array}$ & $\begin{array}{l}\text { The work comes alive in front of the visitor eyes along with their own gestures. "Let's Move Our Works" } \\
\text { is based on Kinect. Like a puppeteer, the visitor gives life to the character of the painting by performing a } \\
\text { few dance steps, perfectly reproduced by this amazing dance partner. Source: https://www.musee- } \\
\text { henner.fr }\end{array}$ \\
\hline $\begin{array}{l}\text { Metamorphy } \\
\text { exhibition }\end{array}$ & $\begin{array}{l}\text { Artistic creation of the } \\
\text { Scenocosme / since } 2013 / \\
\text { presented in different } \\
\text { countries }\end{array}$ & $\begin{array}{l}\text { The gestures of the spectators on the veil make it possible to modify the visual and sound materials in real } \\
\text { time. They vary depending on the location and depth of the pressure generated by the spectators and are } \\
\text { superimposed on the spectator's reflection visible in the mirror. }\end{array}$ \\
\hline $\begin{array}{l}\text { Hugo Pratt } \\
\text { Exhibition }\end{array}$ & $\begin{array}{l}\text { Created by Nokinomo / The } \\
\text { Musée des Confluences / } \\
\text { Lyon (temporary: April 7, } \\
2018 \text { to March 24, 2019) }\end{array}$ & $\begin{array}{l}\text { A table of } 3 \text { meters in diameter presents an interactive video-projected map. It allows visitors to trace } \\
\text { Pratt's different journeys to the four corners of the world and to reveal the characters who were inspired } \\
\text { by. Source: https://www.museedesconfluences.fr/fr/evenements/hugo-pratt-lignes-dhorizons }\end{array}$ \\
\hline $\begin{array}{l}\text { Interactive } \\
\text { library wall, } \\
\text { Dior } \\
\text { exhibition }\end{array}$ & $\begin{array}{l}\text { Musée des arts décoratifs / } \\
\text { Paris (temporary: from July } \\
5,2017 \text { to January } 7,2018 \text { ) }\end{array}$ & $\begin{array}{l}\text { Presented by the } 22 \mathrm{~m} \text { long library wall which incorporates real decor elements, dynamic and interactive } \\
\text { projections. The visitor can interact with the wall, by posing their hand in certain places, and thus generate } \\
\text { light animations, highlight an element of the decor, launch the projection of an archive film. }\end{array}$ \\
\hline $\begin{array}{l}\text { Sketch } \\
\text { Aquarium }\end{array}$ & $\begin{array}{l}\text { Created by teamLab / The } \\
\text { New Children's Museum / } \\
\text { San Diego } 2013 \\
\text { (permanent) }\end{array}$ & $\begin{array}{l}\text { The essence of interactivity: children can draw and color any marine animal they wish. The drawing is } \\
\text { then scanned and projected onto the gigantic virtual aquarium as an animated character. Source: } \\
\text { https://thinkplaycreate.org/explore/art-installations/sketch-aquarium/ }\end{array}$ \\
\hline $\begin{array}{l}\text { Stories } \\
\text { Behind the } \\
\text { Paintings }\end{array}$ & $\begin{array}{l}\text { The National Museum in } \\
\text { Kraków } \\
\text { gallery) / } 2011\end{array}$ & $\begin{array}{l}\text { A virtual reality application that demonstrates how the characters of the paintings come to life and tell a } \\
\text { story related to the works on which they are presented. }\end{array}$ \\
\hline
\end{tabular}

Draft - Authors' version.

Cite final version as: Ten, I., Arbelaez-Garces, G., \& Dupont, L. (2020). Designing interactive museum visitors' experience using a Fab Living Lab platform: the Museum-Aquarium of Nancy case. 2020 IEEE International Conference on Engineering, Technology and Innovation (ICE/ITMC), 1-8. https://doi.org/10.1109/ICE/ITMC49519.2020.9198641 
We can observe from the presented examples that we already have countless examples of the application of new technologies and innovations in the museum experience. The diversity of initiatives show that they can take part in the exhibition to enhance part of the context on which they are present, they can be the experience itself or they can extend the visit beyond the walls of the museum. However, something that is not simply defined is what a museum team should do when faced with the challenge to redesign part of its experience with increased interactivity? Part of the answer to that question lies in the process that should be used. We seek for some answers in the innovation literature.

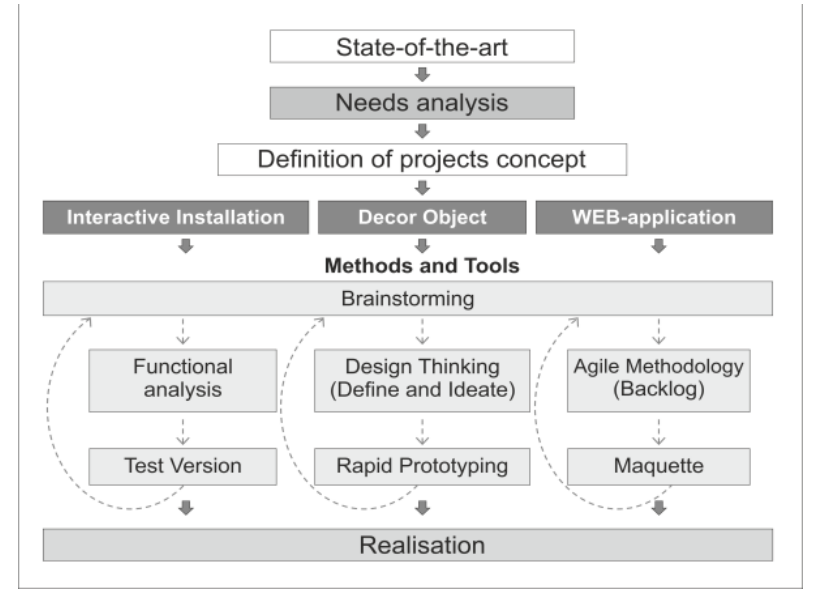

Fig. 1. Representation of different method steps

\section{B. Living Labs, UX and new development practices for museums}

Museums are spaces for knowledge sharing and discussion with the community. The engagement of the community is important to improve the visitor experience and to better understand how to support their learning process [4]. There have been several initiatives to foster community participation in the development of these spaces being the Museomix experience [10] one of the most well-known. Salgado [11] highlighted that museums could foster community participation not only by facilitating the appropriation of information communication technologies (like social media and digital services) but also by engaging the community in the construction of the experience [12]. Living labs offer tools and methods to contribute to the user participation by allowing to prototype and test in an agile manner the new experience concept. Moreover, UX in the cultural domain offers potential frameworks and tools for the analysis of the experience [5], [6]. Fablabs support the creation of temporary artifacts or Boundary Objects (BO) through rapid prototyping technologies like 3D printers or laser cutters.

In the next section, we present our experience with the use of a Fab Living Lab approach supported by the Lorraine Fab Living $\mathrm{Lab}^{\circledR}$ platform (LF2L) [13], [14] in the redesign of the museum experience with increased integration of interactive technologies and experiences. LF2L supports the transition from the abstract idea or concept represented by 2D BO to their materialization in virtual or physical 3D BO by evaluating them through use and over time. In this last case, we talk about 4D BO such as evolution scenarios.

\section{RESEARCH APPROACH}

This work is based on an action research approach [15]. This approach is conceived as a spiral of steps: planning, action, and fact-finding about the results of our action. In this sense, we benefited from a close integration with the museum team and its environment. The action plan, the prototyping stages and the outcomes were made in an agile manner. Indeed, the first author performed the role of the main designer on the museum team and in collaboration with them and the other authors defined the different solutions, the action plans and performed the assessment at each intermediary step to develop the final proposals.

\section{A. Case description}

The "Museum Aquarium de Nancy" is one of the three most important cultural and scientific establishments in Nancy, France. It is managed by the Greater Nancy Metropolitan area in cooperation with the Université de Lorraine. Its collection is composed of 57 aquariums, an exhibition of zoology of 570 animals and a reserve of 136700 animals for conservation, research or temporary exhibitions. The museum is divided into two floors. The first floor is dedicated to the marine and aquarium permanent exhibition, the second floor is divided into the permanent zoological exhibition and a space for temporary exhibitions. In 2018 the museum management staff identified several problems associated with the outdated organization of the museum: the impossibility of presenting large size species and to display their habitat, monotony of the permanent exhibition spaces in contrast with the temporary exhibitions, limited space to display complementary information, website structure. Thus, to tackle these challenges, the museum launched a large-scale project called the "New Organization of Aquarium Galleries" (NOGA). In parallel with this project, we worked on proposing solutions to some of those challenges to include more interactivity in the visitor experience and to explore the inclusion of digital technologies. In the next section, we will present the development of three solutions.

Draft - Authors' version.

Cite final version as: Ten, I., Arbelaez-Garces, G., \& Dupont, L. (2020). Designing interactive museum visitors' experience using a Fab Living Lab platform: the Museum-Aquarium of Nancy case. 2020 IEEE International Conference on Engineering, Technology and Innovation (ICE/ITMC), 1-8. https://doi.org/10.1109/ICE/ITMC49519.2020.9198641 
The development of the projects was grounded on the following design frameworks: Experience Design, User Experience, Digital Transformation, and Rapid Prototyping. The general approach used is summarized in Figure 1, it can be divided into five steps: State of the art, Need analysis, the definition of project concepts, development of each concept, and realization.

The first step, state-of-the-art allowed us to benchmark the current state of the museum experience, to identify current trends and the overall picture of the development and impact of new technologies on the functioning of public institutions. Some of the experiences that were presented in Table I were found in this initial step.

After the first stage, we performed a needs analysis aimed at identifying and structuring the primary and additional needs of potential users and visitors to the museum. The third stage is represented by the formalization of the design concepts for three projects, in this step we worked on the emergence of ideas and the definition of their overall features and characteristics.

The fourth step was an in-depth work on each project concept intended to formalize the design specifications. At this stage, different approaches to be suited to the particularities of each project were used (e.g. Functional analysis, Design Thinking, and Agile Methodologies). An important element in this phase was the use of prototyping as it helped to test and refine the design specifications with the different museum staff and visitors. The prototyping phase was made using the digital manufacturing capabilities of the LF2L. This allowed us to assess different aspects with regards to feasibility, types of technologies used, the evolution of the concept idea and the appearance of the final result. The final proposals were then formalized in a specification requirements document and proposed as a public call for tenders to implement the final versions that were made available at the museum.

The fifth step was performed by the different developers and suppliers that were selected in the call for tenders. Their work was to fully implement and deploy the projects in the museum according to the design specifications that were given with the example of the developed prototypes and respecting the local constraints for public cultural spaces.

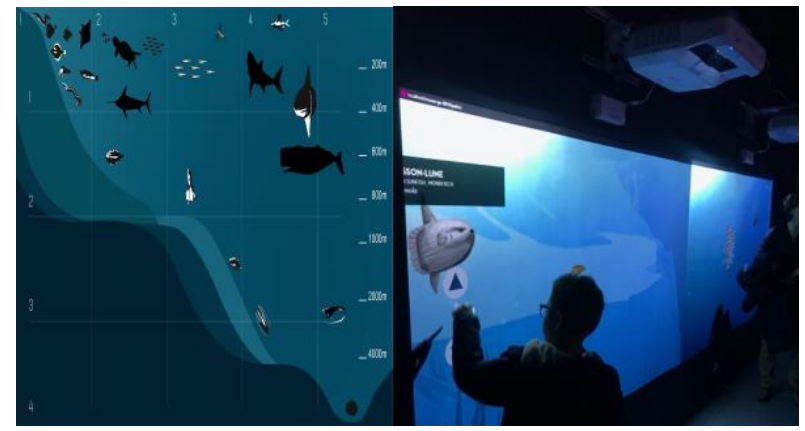

Fig. 2. Interactive projection prototype (2D BO) and final version at the MAN (4D BO)

\section{FINDINGS}

The result of this work was the development of three digital interactive experiences at the MAN, which includes an interactive video projection, a web application, and a decorative interactive object. In this section, we detail the concept definition and prototyping phases for each of those solutions.

\section{A. Interactive video projection}

The Interactive video projection is intended as a pedagogical tool providing scientific information in a simplified visual form and to allow the visitors to be involved in the learning process. Its aim is to show the Atlantic Ocean in cross-section, to allow visitors to study its different levels of depth, as well as certain representatives of its marine fauna, which cannot be represented in the gallery in its real format (cf. figure 2). The video projection is presented as a series of animations, each of which launches by touching the image of one or another image of the sea creatures. The animation demonstrates the particular behavior of this species, which explains its adaptation to certain environmental conditions.

The prototyping stage allowed us to see clearly the subtleties and features of the solution, which, in turn, contributed to a more detailed description of the project specifications and, therefore, to the optimization of the implementation process. The test version of the animation for the interactive video projection was created in Adobe Flash Professional CS5.5 in SWF format. The file consists of animated graphics and some scripts that are responsible for the interactive part of the animation. The animation starts when we click on a static image. For the prototypes several versions were developed, initially, tests of the animations only were shown to the museum team in a computer screen. Then some tests were done with interactive video projectors that were made available by the University of Lorraine, the test allowed us to anticipate some potential problems of the displays in the museum. Figure 2 presents also the final implemented version in the museum.

Draft - Authors' version.

Cite final version as: Ten, I., Arbelaez-Garces, G., \& Dupont, L. (2020). Designing interactive museum visitors' experience using a Fab Living Lab platform: the Museum-Aquarium of Nancy case. 2020 IEEE International Conference on Engineering, Technology and Innovation (ICE/ITMC), 1-8. https://doi.org/10.1109/ICE/ITMC49519.2020.9198641 


\section{B. WEB application}

The web application is a platform for storing additional scientific information concerning each species presented in the gallery of the museum. This solution intended to provide complementary information during and after the visit. Every visitor has access to the information in the application via their own smartphone, as well as via tablets installed in the museum at several informative points. In addition, due to the limited size of the panels with descriptive information that is present in the museum, the application enabled the use of two foreign languages (English and German) to present the information. Since the museum is on the list of the most important institutions that contribute to the tourist potential of the territory, adapting the museum to foreign visitors was an absolute requirement for this solution.

In the prototyping stage, an organizational chart for the web application structure was developed. In addition, an initial

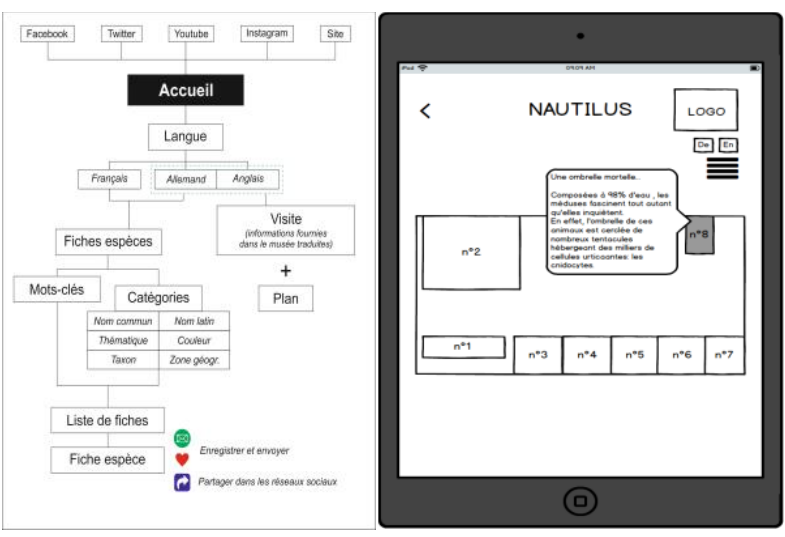

Fig. 3. System architecture and layout mockup for the web app (2D BO) layout of the application interface was developed using Balsamiq a wireframing software (cf. Figure 3). These prototypes served as a means for discussion of the interfaces and the functionalities with the different stakeholders and it allowed to coordinate the work of the developers.

\section{Decorative interactive object}

The final concept was intended to propose an interactive object that would allow filling a part of the museum's space intended as an intermediary resting area along with the visit. The aim was to propose a decorative element linked to the team of the space but that would propose a "surprising" and playful experience in order to enhance the hedonic quality of the visitors" experience [16].

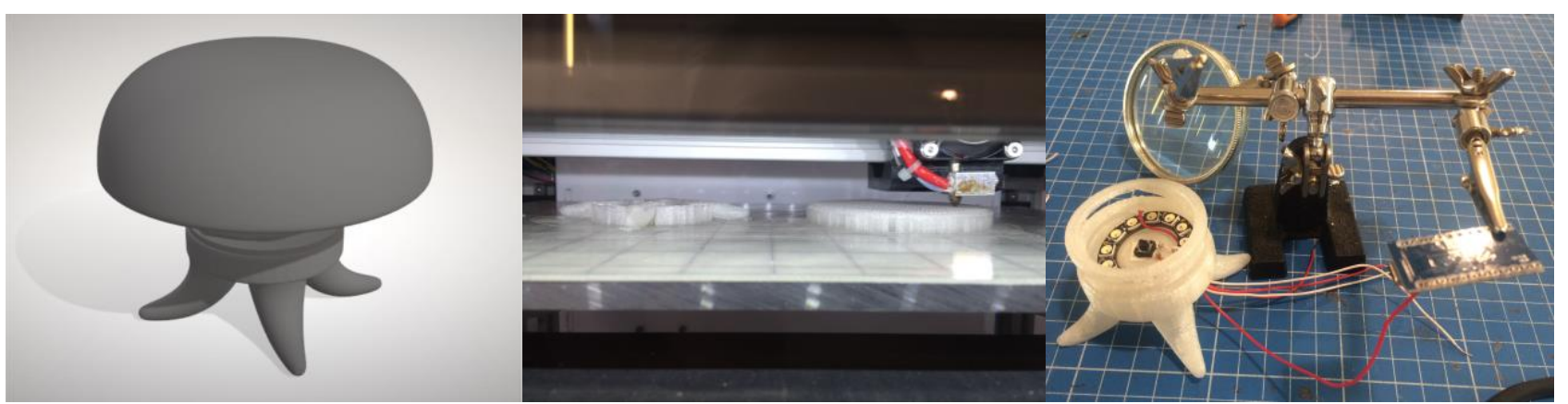

Fig. 4. Decorative interactive object prototypes: 3D model (virtual 3D BDO), rapid prototyping, electronics testing (two stages Stakeholders interactions

As a decorative object it should appeal to the visitor, making it feel at ease and makes the visit, and the atmosphere as a whole, more pleasant and attractive. The concept developed for the object was a seat in the shape of a jellyfish. When someone is seated on it, a LED light up in the center of the seat illuminating the entire object. The seat material must be translucent so that the light could be visible. During the development of this object, a prototype was created on a reduced scale. We used Autodesk 3Ds Max software to do a 3D model. Then we used two 3D printers (Open Edge ALTO and Open Edge HD 2.0) to prototype different versions and materials. The final prototype used: PLA White $1,75 \mathrm{~mm}$. To test the interactivity for the lighting system, we made some electronic prototypes. The electronic components of the prototype used were LEDs (NeoPixel Ring), PRO Micro Module (Arduino Leonardo Board), Micro USB Adapter Charger (5v 2000mA), Push Button Switch (Tact Switch 5mm). Figure 4 presents the different stages of the prototype.

The final proposals were all formalized in a specification requirements document and proposed as a public call for tenders to implement the final versions. For the interactive wall and the web page they were developed and implemented in the museum, they are presented since the reopening in 2019. For the decorative interactive object, it was difficult to find a company or artist that was able to implement it in full scale and on time for the reopening, but the museum is currently discussing with local designers and artist to see if it can be finally implemented.

Draft - Authors' version.

Cite final version as: Ten, I., Arbelaez-Garces, G., \& Dupont, L. (2020). Designing interactive museum visitors' experience using a Fab Living Lab platform: the Museum-Aquarium of Nancy case. 2020 IEEE International Conference on Engineering, Technology and Innovation (ICE/ITMC), 1-8. https://doi.org/10.1109/ICE/ITMC49519.2020.9198641 


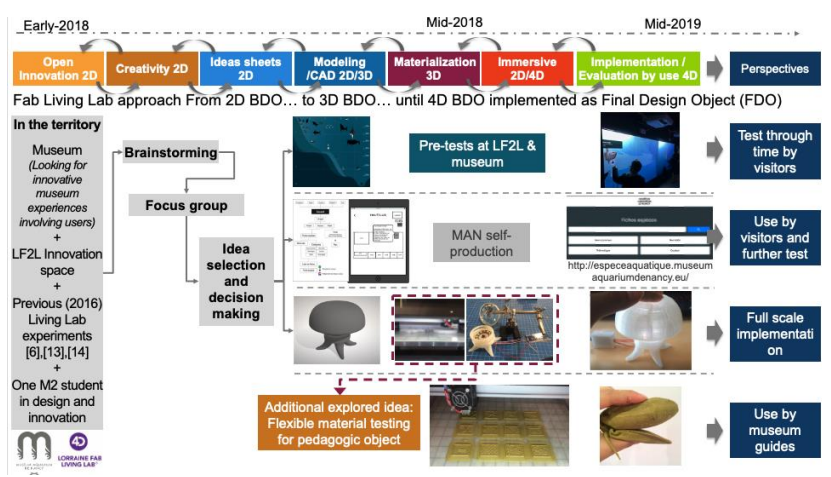

Fig. 5. Fab Living Lab process BO evolution in 2018-2019 (larger version in last page)

\section{Discussion}

Figure 5 presents the development process structured through the Fab Living Lab approach phases [13], [14]. It shows how the different projects emerged and evolved from a simple idea to something that takes a form that can be tested. It goes from a simple sketch or a more detailed CAD model to an object that allows testing and interacting with. The figure shows that after the ideation phases there was an idea selection and decision-making step with the museum stakeholders to select the concepts to be developed. Even if the figure seems linear, it was not, there were several back and forth between the different phases. In particular, from the testing phase to modifications in the designs. Additionally, we can observe that there was a project that was not presented before that emerged during the materialization phase. Indeed, during this phase, while testing some materials it seemed interesting to try flexible printing materials to print some fish forms as they could be used by the museum guides during the explanation with some groups. These objects were well received by the guides that use them to explain some fish movements during visits. Those findings correspond to what has been highlighted in the literature about the role prototypes or boundary objects play in the design process and their importance at each design stage [17], [18].

This study shows also that opening up an innovation space (LF2L) supported by a Fab Living Lab approach can help different actors in a territory to collaborate and innovate at different levels [19]. In the case of the student that worked on the project it allowed it to develop professional experience through the case. The museum benefited to access to the innovation space and the competencies necessary to explore its ideas before using the public procurement procedure, which is governed by fairly lengthy regulations and procedures and sometimes reduces the possibility of setting up initiatives that are too innovative. The innovation space had access to new cases in the domain of cultural heritage and to explore those ideas. The collaboration also allowed us to accelerate the innovation in the museum by allowing us to explore some of the concepts, to test them and to modify them thus giving more elements related to real use of those ideas to support the decision making. These last findings, corresponds to what has ben highlighted in the Living Labs literature in two aspects: first, it shows that the Fab Living Lab approach contributes to create a collaborative learning in the project shared by all the actors [20]; second, it creates a dynamic to allow the project to be "agile" by allowing to transform the solution according to the changing perspectives and uncertainties of all the stakeholders and not being tied to a preconceived solution form the beginning [21].

Finally, while the learnings from a single case doesn't allow to generalize nor compare to understand what difference can make to use the Fab Living Lab approach. The work of [18] provides some answers, showing that while this type of approaches don't take away all the difficulties that a collaborative project have (e.g. collaborative decision making, collaboration arrangements, effective boundary spanners, conflict resolution), living labs makes it easier to tackle those challenges.

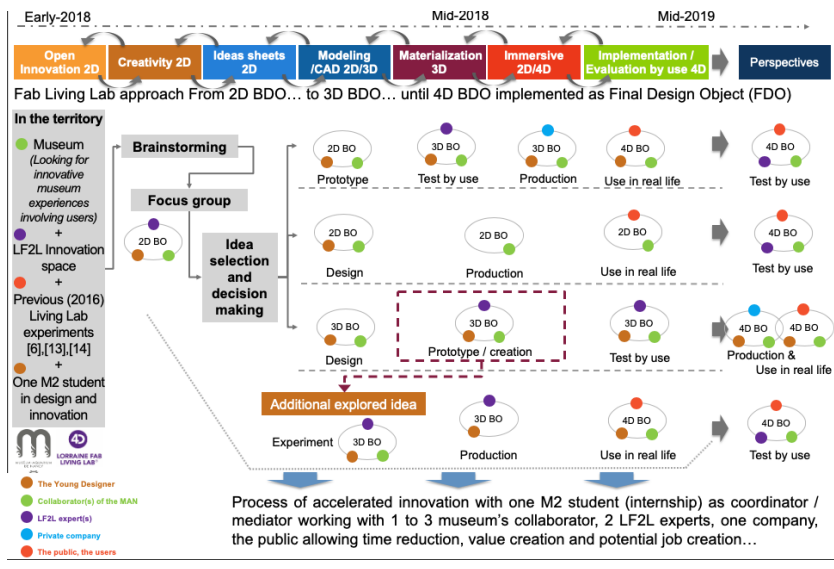

Fig. 6. Stakeholders interactions during the process (larger version in las page)

Draft - Authors' version.

Cite final version as: Ten, I., Arbelaez-Garces, G., \& Dupont, L. (2020). Designing interactive museum visitors' experience using a Fab Living Lab platform: the Museum-Aquarium of Nancy case. 2020 IEEE International Conference on Engineering, Technology and Innovation (ICE/ITMC), 1-8. https://doi.org/10.1109/ICE/ITMC49519.2020.9198641 
Another way to observe the dynamics of interactions that occurred in the project between the different stakeholders through the $\mathrm{BO}$ is shown in Figure 6. We can observe that the young designer, which was the project coordinator, is permanently present. He thus plays the role of mediator with the help of the BOs. In fact, the system to which the young professional (Master student) had access made it possible to mobilize few actors (1 to 3 museum's collaborators, 2 LF2L experts, one company) while maximizing the results of the design process for an enhanced visitor experience. Furthermore, in perspectives we identify for each project the necessary interactions that could happen with the current BO to test and improve the projects in their current state.

This study has also a real impact on the territory because the collaboration forms, all the methods, technologies are capitalized in the innovation space and are thus accessible to other actors in the territory (e.g. SMEs, other institutions, schools). In the museum, this type of experimentation reinforces the attractiveness of the place, it encourages them to create new experiences, it helps to familiarize the younger audiences with new interactive experiences.

\section{CONCLUSION AND PERSPECTIVES}

Digital technologies are opening up completely new perspectives in the development of museum experiences. They can impact influencing the overall functionality of these institutions at different levels [22]. They allow, on the one hand, to diversify the visit to the museum, and on the other hand, to simplify or facilitate the work of its staff. However, as examples have shown, visitors of museums, cultural and scientific institutions are becoming more demanding [3]. That is, if previously, the installed screen or tablet caused them surprise and interest, today these attributes are a natural phenomenon and no longer cause a similar reaction. Thus, confronting the museums to take into account this phenomenon in their offer.

In this work, we presented part of the process behind the redesign experience of the MAN. We detail in particular the process behind the design and development of three projects: an interactive video projection, a web application, and a decorative interactive object.

The presented work shows an approach that draws from the innovation and living lab literature employing user experience design and agile tools. It was shown that in particular, the prototyping phase plays an important role by providing Boundary Objects (i.e. prototypes, mockups, sketch) that allow aligning the different viewpoints of all the stakeholders [23]. They were also useful to guide the work in the commissioning process by allowing to fully convey the vision and expectations regarding the outcome.

This last part is an important change in the process of the MAN because being a public cultural institution the commissioning work is a required step for the implementation of the proposals. But in the past, the design brief in the call for tenders was more open (least detailed) which sometimes brought good surprises, but in other opportunities was also a source for not so good outcomes. By opening up the design and prototyping process before the writing of the design specifications allowed the museum to have more control over the outcome and allowed deeper participation of the museum staff and visitors in the definition of the solutions.

In further work, it would be necessary to create dedicated spaces to imagine continually the development of new experiences in the museum. Why not making the testing of those prototypes part of the experience? Additionally, in further research, it would be necessary to better include a framework of analysis of the visitors' experience [5] to better assess the outcomes.

\section{ACKNOWLEDGMENT}

Authors would like to thank the MAN managers, collaborators and to all the museum visitors that participated in the development of the experiences. Special thanks to the Lorraine Fab Living Lab® team for providing the tools and helping to develop the different prototypes. I Ten was an intern at the MAN during the realization of the project and as such benefited from financial support from the institution. The LF2L benefited from the support of ENSGSI, ERPI and Métropole du Grand Nancy.

\section{REFERENCES}

[1] G. Bast, E. G. Carayannis, and D. F. J. Campbell, Eds., The Future of Museums. Cham: Springer International Publishing, 2018.

[2] M. Brinkerink and K. Drost, "Labs as an Agile Instrument to Supercharge the Development of a Tech Heavy Museum: Making informed choices by failing early and learning by doing," MW19: MW 2019. Published March 22, 2019. [Online]. Available: https://mw19.mwconf.org/paper/labs-as-anagile-instrument-to-supercharge-the-development-of-a-tech-heavy-museum-making-informed-choices-by-failing-early-and-learning-by-doing/. [Accessed: 29-Jan-2020].

[3] T. Giannini and J. P. (Jonathan P. Bowen, Museums and Digital Culture. Cham: Springer International Publishing, 2019.

[4] J. H. Falk and L. D. Dierking, The Museum Experience Revisited. Routledge, 2016

[5] M. Konstantakis and G. Caridakis, "Adding Culture to UX: UX Research Methodologies and Applications in Cultural Heritage," J. Comput. Cult. Herit., vol. 13, no. 1, 2020, doi: https://doi.org/10.1145/3354002.

[6] P. Parra, S. A. Peñarete, G. Arbelaez Garces, M. Camargo, and L. Dupont, “Understanding Museum visitors' experience through an Eye-tracking study and a Living Lab approach," in 22nd ICE/IEEE International Technology Management Conference. 13-15 June., 2016.

[7] M. Gascó, "Living labs: Implementing open innovation in the public sector," Gov. Inf. Q., vol. 34, no. 1, pp. 90-98, 2017, doi: 10.1016/j.giq.2016.09.003.

[8] M. Hirose, "Virtual Reality Technology and Museum Exhibit," Int. J. Virtual Real., vol. 5, no. 2, pp. 31-36, Jan. 2006, doi: 10.20870/IJVR.2006.5.2.2686.

[9] M. Despina, N. Pelekanos, I. Chrysanthou, P. Zaharias, L. L. Hadjigavriel, and Y. Chrysanthou, "Comparative Study of Interactive Systems in a Museum," in Digital Heritage, vol. 6436, M. Ioannides, D. Fellner, A. Georgopoulos, and D. G. Hadjimitsis, Eds. Berlin, Heidelberg: Springer Berlin Heidelberg, 2010, pp. 250-261.

[10] S. Chaumier and C. Françoise, "Museomix : l'invention d'un musée du XXIe siècle," La Lett. l'OCIM, no. 156, pp. 7-11, Nov. 2014, doi: Draft - Authors' version.

Cite final version as: Ten, I., Arbelaez-Garces, G., \& Dupont, L. (2020). Designing interactive museum visitors’ experience using a Fab Living Lab platform: the Museum-Aquarium of Nancy case. 2020 IEEE International Conference on Engineering, Technology and Innovation (ICE/ITMC), 1-8. https://doi.org/10.1109/ICE/ITMC49519.2020.9198641 
10.4000/ocim.1454.

[11] M. Salgado, "Museums as Living Labs Challenge, Fad or Opportunity?," The Journal of Community Informatics, vol. 9, no. 3. 05-Feb-2013.

[12] M. Salgado, Designing for an open museum: an exploration of content creation and sharing through interactive pieces. Jyväskylä, Finland: Taideteollinen korkeakoulu, 2009.

[13] L. Dupont, L. Morel, and P. Lhoste, "Le Lorraine Fab Living Lab : la 4ème dimension de l'innovation," in Actes des sessions du colloque Science \& You, France, 2015, pp. 230-235.

[14] L. Dupont, M. Pallot, L. Morel, and M. Pallot, "Exploring the Appropriateness of Different Immersive Environments in the Context of an Innovation Process for Smart Cities," in 22nd ICE/IEEE International Technology Management Conference, 2016.

[15] K. Lewin, “Action Research and Minority Problems,” J. Soc. Issues, vol. 2, no. 4, pp. 34-46, Nov. 1946, doi: 10.1111/j.1540-4560.1946.tb02295.x.

[16] M. Hassenzahl and N. Tractinsky, "User experience - a research agenda," Behav. Inf. Technol., vol. 25, no. 2, pp. 91-97, 2006, doi: $10.1080 / 01449290500330331$.

[17] A. Häggman, T. Honda, and M. C. Yang, "The Influence of Timing in Exploratory Prototyping and Other Activities in Design Projects," in Volume 5: 25th International Conference on Design Theory and Methodology; ASME 2013 Power Transmission and Gearing Conference, 2013, doi: 10.1115/DETC2013-12700.

[18] S. Hyysalo and L. Hakkarainen, "What difference does a living lab make? Comparing two health technology innovation projects," CoDesign, vol. 10, pp. 191-208, 2014, doi: 10.1080/15710882.2014.983936.

[19] F. Osorio, L. Dupont, M. Camargo, P. Palominos, J. I. Peña, and M. Alfaro, "Design and management of innovation laboratories: Toward a performance assessment tool," Creat. Innov. Manag., vol. 28, no. 1, pp. 82-100, Mar. 2019, doi: 10.1111/caim.12301.

[20] L. Delgado, D. Galvez, A. Hassan, P. Palominos, and L. Morel, "Innovation Spaces in Universities: Support for Collaborative Learning," J. Innov. Econ. Manag., vol. $\mathrm{n}^{\circ} 31$, no. 1, p. 123, 2020, doi: 10.3917/jie.pr1.0064.

[21] L. Dupont, "Agile innovation: Creating value in uncertain environments," J. Innov. Econ., vol. 28, no. 1, p. 1, 2019, doi: 10.3917/jie.028.0001.

[22] B. Dawson and D. Edmundson, "Building A Smart Museum: Tackling In-Gallery Challenges With Digital Experience At Scale," MW18: MW 2018. Published March 16, 2018. [Online]. Available: https://mw18.mwconf.org/paper/building-a-smart-museum-tackling-in-gallery-challenges-with-digitalexperience-at-scale/. [Accessed: 28-Jan-2020].

[23] S. L. Star and J. R. Griesemer, “Institutional Ecology, 'Translations' and Boundary Objects: Amateurs and Professionals in Berkeley's Museum of Vertebrate Zoology, 1907-39,” Soc. Stud. Sci., vol. 19, no. 3, pp. 387-420, Aug. 1989, doi: 10.1177/030631289019003001. 
Fig 5 and Fig 6 large versions.

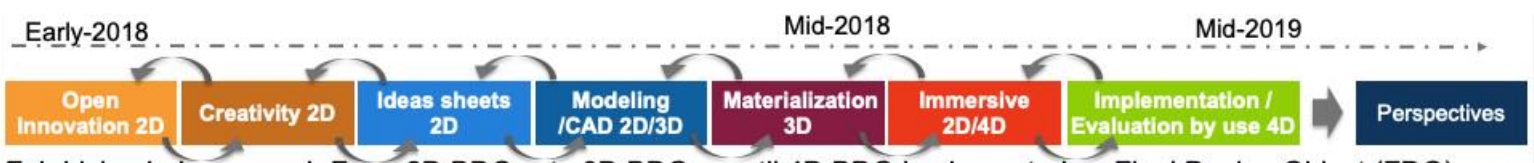

Fab Living Lab approach From 2D BDO... to 3D BDO... until 4D BDO implemented as Final Design Object (FDO)
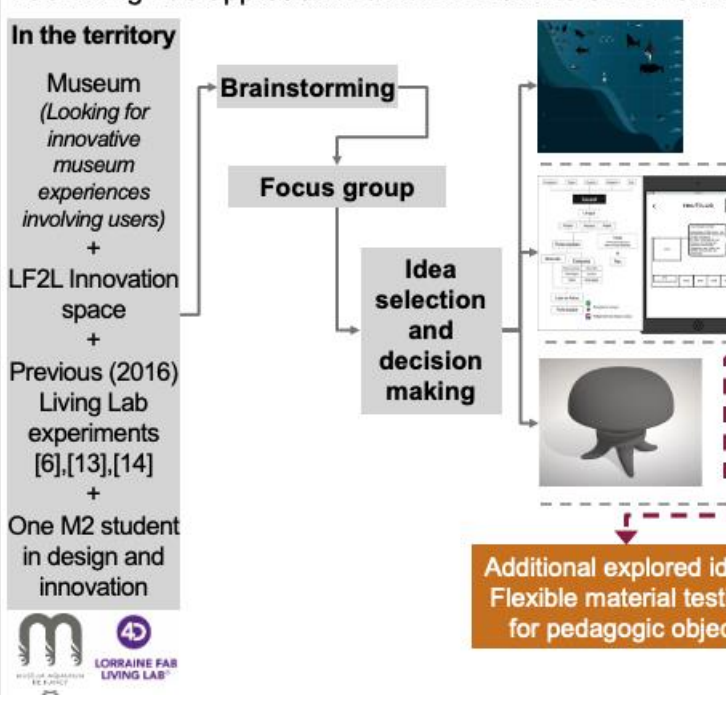

(

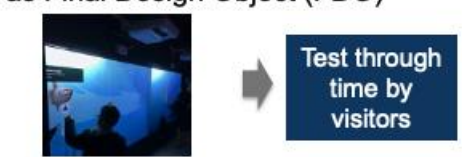

ests at LF2L \& museum

visitors

Fig. 5. Fab Living Lab process BO evolution in 2018-2019

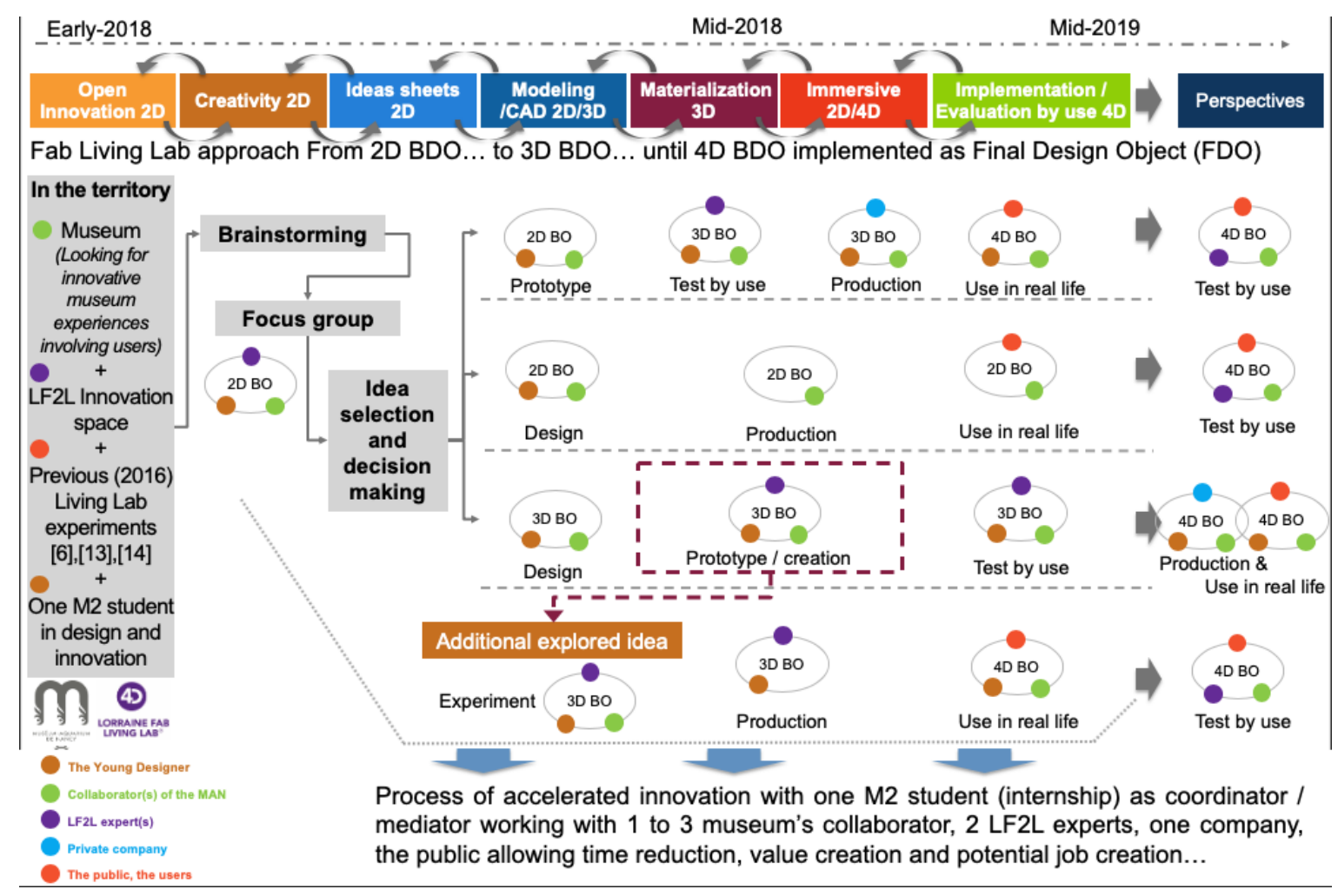

Fig. 6. Stakeholders interactions during the process

Draft - Authors' version.

Cite final version as: Ten, I., Arbelaez-Garces, G., \& Dupont, L. (2020). Designing interactive museum visitors' experience using a Fab Living Lab platform: the Museum-Aquarium of Nancy case. 2020 IEEE International Conference on Engineering, Technology and Innovation (ICE/ITMC), 1-8. https://doi.org/10.1109/ICE/ITMC49519.2020.9198641 